\title{
Comparison between esmolol and verapamil in attenuation of cardiovascular stress response to laryngoscopy and endotracheal intubation in elective surgery
}

\author{
Nitisha Chakraborty ${ }^{1}$, Sankar Roy², Debajyoti Sur ${ }^{3}$, Arunava Biswas ${ }^{4}$, \\ Dipasri Bhattacharya ${ }^{5}$, Anjan Adhikari ${ }^{6}$ \\ ${ }^{1}$ Senior Resident, Department of Anesthesiology, Critical Care \& Pain, R.G. Kar Medical College \& Hospital, Kolkata, \\ West Bengal, India, ${ }^{2}$ Associate Professor, ${ }^{3}$ Assistant Professor, ${ }^{5}$ Professor, Department of Anesthesiology, R. G. \\ Kar Medical College \& Hospital, Kolkata, West Bengal, India, ${ }^{4}$ Associate Professor, ${ }^{6}$ Professor, Department of \\ Pharmacology, Maharaja Jitendra Narayan Medical College \& Hospital, Coochbehar, West Bengal, India
}

A B S TR A C T

Background: Cardiovascular stress due to reflex sympathetic over activity is a great concern during laryngoscopy and endotracheal intubation. Aims and Objectives: To compare the efficacy and safety of esmolol and verapamil for attenuation of hemodynamic effects (heart rate, systolic blood pressure, diastolic blood pressure and mean arterial pressure) due to laryngoscopy and endotracheal intubation in elective surgical cases. Materials and Methods: A prospective, randomized, double blinded, controlled study was conducted on 60 patients divided equally into 30 each receiving esmolol $(2 \mathrm{mg} / \mathrm{kg}$ body weight) and verapamil $(0.1$ $\mathrm{mg} / \mathrm{kg}$ body weight) respectively. Heart rate, systolic and diastolic blood pressure and mean arterial pressure were recordedat pre-operative stage, after administration of the study drugs, immediately after intubation and at $1,3,5$ minutes after intubation. Data collected were statistically analyzed. Results: The mean systolic blood pressure was lower in the esmolol group at all times of estimation compared with the verapamil group and the difference was at the time of intubation ( $p$ value $<0.001$ ). The mean diastolic blood pressure was lower in the esmolol group at all times of estimation compared to the verapamil group which was not statistically significant at any time of estimation. The mean arterial pressure was significantly lower at the time of immediately after intubation $(p<0.001)$ in esmolol as compared to verapamil group. Adverse effects in both the study groups were insignificant. Conclusion: Esmololand Verapamil can effectively attenuate the cardiovascular stress to laryngoscopy and endotracheal intubation with the former appears to be a better alternative from efficacy and safety perspectives.

Key words: Esmolol; Verapamil; Cardiovascular stress; Laryngoscopy; Endotracheal intubation

\section{INTRODUCTION}

Rigid laryngoscopy and tracheal intubation still remain the gold standard in airway management. The influence of airway manipulation on heart rate and blood pressure was recognized more than 50 years ago and the magnitudes of the changes were observed to depend on the depth of anesthesia. ${ }^{1}$ It is now well established that laryngoscopy and endotracheal intubation violate patient's protective reflexes and invariably cause hemodynamic changes associated with increased heart rate, increased blood pressure and occasional disturbances in cardiac rhythm. These hemodynamic changes rise as a form of sympathoadrenal reflex and due to release of norepinephrine and to a lesser extent epinephrine. ${ }^{2}$ In normotensive subjects these hemodynamic changes are short lived and probably of little significance. ${ }^{3}$ 
However, these hemodynamic alterations are hazardous to the patients with hypertension, myocardial insufficiency or cerebrovascular disease. Laryngoscopy and intratracheal intubation are known to result in transient hypertension, tachycardia and arrhythmias which can be deleterious in patients with coronary heart disease, cerebrovascular accident or aortic and intracranial aneurysms. ${ }^{4}$

In patients with coronary artery disease, it may lead to myocardial ischemia and dysrhythmia because, increase in heart rate and blood pressure associated with laryngoscopy and endotracheal intubation may result in an increase in myocardial oxygen demand and also demand for increased coronary flow. In hypertensive patients these exaggerated responses may lead to left ventricular failure, pulmonary edema and congestive cardiac failure. In patients with intracranial aneurysm or dissecting aneurysm of the aorta, the increase in systemic blood pressure may cause rupture of vessels with life threatening consequences. The magnitude of response is greater with increasing force and duration of laryngoscopy. Elevation of blood pressure and heart rate typically starts within 5 seconds of laryngoscopy, peaks in 1 to 2 minutes and return to baseline level within 5-10 minutes.

So, effective attenuation of the sympathoadrenal stress response is an important goal in anesthesiology. Various pharmacologic and non pharmacologic methods have been tried to limit the vasopressor response following the insertion of endotracheal tube. ${ }^{5}$ The success rate is variable with different methods because each method has its own merits and demerits. In several trials drugs like opioids, lidocaine, nitrates, calcium channel blockers, alpha-2 adrenergic agonists, beta blockers, deep anesthesia or magnesium have been used orally or parenterally to obtund these sympathoadrenal responses. ${ }^{6-10}$ Among the calcium-channel blockers, nifedipine, verapamil, diltiazem and nicardipine have been used.

Esmolol is a cardio selective $\beta_{1}$ adrenergic receptor blocker with rapid onset and a short duration of action. Esmolol has also been used in various studies for attenuation of these reflexes. However, no consensus has been reached regarding optimum dose, the mode or timing of its delivery. ${ }^{11}$ There have been studies which have assessed the role of esmolol and verapamil separately as regards the attenuating response, but no study has yet compared these two drugs by way of outcome assessment.

Therefore, this study was conducted to compare the efficacy and safety of esmolol and verapamil for attenuation of hemodynamic effects (heart rate, systolic blood pressure, diastolic blood pressure and mean arterial pressure) due to laryngoscopy and endotracheal intubation in elective surgical cases.

\section{MATERIALS AND METHODS}

A prospective, randomized, double blinded, controlled study was conducted on $(n=60)$ patients of either sex aged $40-70$ years with ASA Grade I or II, willing to give written consent for participation and selected for elective abdominal surgery at operation theater of K.P.C Medical College and Hospital, Kolkata. during July 2016 to August 2017. Patients with history of diabetes mellitus, hypertension, respiratory disorders, raised intracranial tension, allergy to study drugs, pregnancy and history of anticoagulant therapy were excluded from the study.

After receiving approval from the Institutional Ethical Committee based of inclusion/exclusion criteria patients were randomly allocated using online software Random ${ }^{\circ}$ into 2 equal-sized groups of 30 patients in each group $(n=30)$. Group E received Inj. Esmolol $2 \mathrm{mg} / \mathrm{kg}$ body weight and Group V received Inj. Verapamil $0.1 \mathrm{mg} / \mathrm{kg}$ body weight intravenous bolus dose 2 minutes before laryngoscopy and intubation. The anesthetist who administered the study drugs was blinded regarding participant's group allocation. All patients were pre oxygenated for 5 min with $100 \%$ oxygen and premedicated with injection glycopyrrolate $0.2 \mathrm{mg}$ and injection midazolam $1 \mathrm{mg}$, prior to induction of anesthesia. Heart rate, systolic and diastolic blood pressure and mean arterial pressure were recorded as baseline values. Bispectral Index (BIS) was used for monitoringthe depth of anesthesia. The target BIS range was 40-60for surgical anesthesia.

Inj. fentanyl citrate $2 \mathrm{mcg} / \mathrm{kg}$ intravenously and induction was done with inj.propofol $2 \mathrm{mg} / \mathrm{kg}$ at a rate of $20 \mathrm{mg} / 5$ second until BIS was below60. Endotracheal intubation was facilitated with inj. succinylcholine $1 \mathrm{mg} / \mathrm{kg}$. Anesthesia was maintained with inj. atracurium $0.5 \mathrm{mg} / \mathrm{kg}$ as intermediate acting muscle relaxant in bolus and intermittent dose and nitrous oxide and oxygen at the ratio of $66 \%$ and $33 \%$ respectively. Isoflurane, aninhalational anesthetic was given to maintain the BIS at the range of 40-60.At the end of surgery, reversal was done with neostigmine $0.05 \mathrm{mg} / \mathrm{kg}$ and atropine $0.02 \mathrm{mg} / \mathrm{kg}$ and send to post anesthetic care unit (PACU).All parameters of the study were recorded at pre-operative, after administration of the study drugs, immediately after intubation and at 1, 3, 5 minutes after intubation.

\section{Statistical analysis}

Statistical Package for Social Sciences (SPSS) version 11.5 software was used for analysis of data and variables were analyzed by Student t-test and paired t-test. P value of $<0.05$ was taken as statistically significant. 


\section{RESULTS}

A total $(n=60)$ patient was recruited in this study divided equally into two groups with $(n=30)$ each. Demographic parameters of the study participants were statistically insignificant between the study groups (Table 1).

The baseline parameters including HR, SBP and DBP before intubation were well matched between the two-study groups (Tables 2-4). A change in the mean heart rate at different time interval is depicted in Figure 1. Variation in heart rate was insignificant in the group $\mathrm{V}$ patients whereas in group $\mathrm{E}$ it remained below baseline during the period of assessment.

In (Table 2) it shows that the mean SBP (Systolic Blood Pressure) was lower in the Esmolol group at all times of estimation compared to the Verapamil group. The difference was not statistically significant in any point of time except at the time of intubation ( $p$ value $<0.001)$.

Table 3 shows that the mean DBP (diastolic blood pressure) was lower in the esmolol group at all times of estimation compared to the verapamil group. The difference was not statistically significant at any time of estimation.

The MAP (mean arterial pressure) as shown in Table 4 was lower in the esmolol group at all times of estimation compared to the verapamil group. The difference was

\begin{tabular}{|c|c|c|c|}
\hline $\begin{array}{l}\text { Demographic } \\
\text { Parameters }\end{array}$ & $\begin{array}{c}\text { Group-E } \\
\text { (mean } \pm \text { SD) } \\
(n=30)\end{array}$ & $\begin{array}{c}\text { Group-V } \\
(\text { mean } \pm \text { SD) } \\
(n=30)\end{array}$ & $p$-value \\
\hline Age (in years) & $47.47 \pm 4.85$ & $47.33 \pm 5.15$ & 0.92 \\
\hline $\begin{array}{l}\text { Gender } \\
\text { (Male: Female) }\end{array}$ & $14: 16$ & $17: 13$ & 0.43 \\
\hline ASA Grade (I: II) & $22: 8$ & $22: 8$ & 0.99 \\
\hline
\end{tabular}

\begin{tabular}{|c|c|c|c|}
\hline $\begin{array}{l}\text { Time Interval } \\
\text { SBP (mm Hg) }\end{array}$ & $\begin{array}{c}\text { Group-E } \\
(\text { mean } \pm \text { SD) } \\
(n=30)\end{array}$ & $\begin{array}{c}\text { Group-V } \\
(\text { mean } \pm \text { SD) } \\
(n=30)\end{array}$ & $p$-value \\
\hline Basal & $121.60 \pm 11.76$ & $125.03 \pm 4.65$ & 0.14 \\
\hline Post drug & $121.10 \pm 11.22$ & $125.40 \pm 8.56$ & 0.10 \\
\hline Intubation & $106.97 \pm 10.58$ & $146.77 \pm 14.05$ & $<0.001^{*}$ \\
\hline $\begin{array}{l}1 \text { minute after } \\
\text { intubation }\end{array}$ & $130.73 \pm 8.06$ & $132.83 \pm 9.40$ & 0.35 \\
\hline $\begin{array}{l}3 \text { minutes after } \\
\text { intubation }\end{array}$ & $126.23 \pm 8.19$ & $127.53 \pm 8.77$ & 0.55 \\
\hline $\begin{array}{l}5 \text { minutes after } \\
\text { intubation }\end{array}$ & $123.93 \pm 6.11$ & $126.43 \pm 6.08$ & 0.11 \\
\hline
\end{tabular}

statistically significant at the time of immediately after intubation $(\mathrm{p}<0.001)$.

The proportion of patients with bradycardia and shivering were higher in esmolol group as compared to the other group as shown in Table 5 , but it was not statistically significant ( $\mathrm{p}=0.12,0.27$ respectively). Proportion of patients with hypoxemia was higher in verapamil group as compared to esmolol group, but it was not statistically significant $(\mathrm{p}=0.27)$.

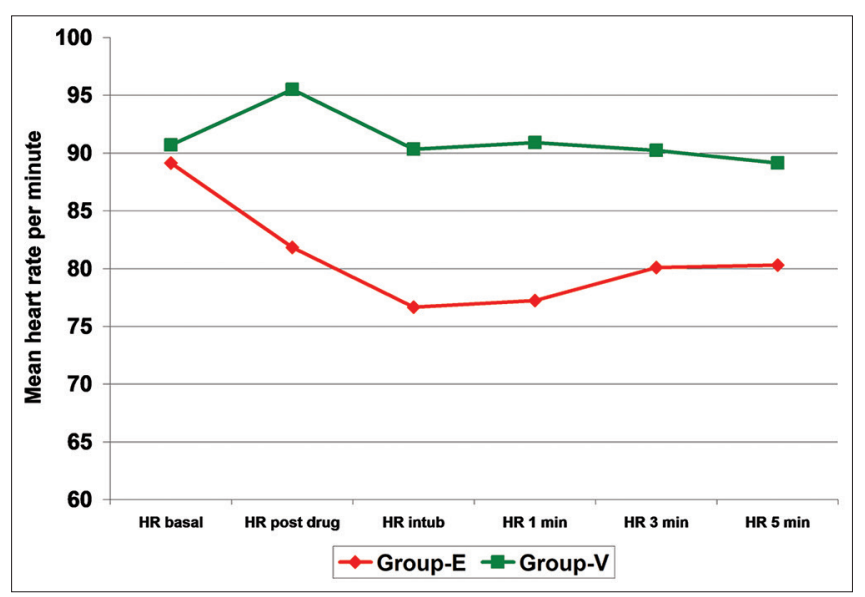

Figure 1: Changes in mean heart rate at different times in the two study groups

\begin{tabular}{|c|c|c|c|}
\hline $\begin{array}{l}\text { Time Interval } \\
\text { DBP } \\
(\mathrm{mm} \mathrm{Hg})\end{array}$ & $\begin{array}{c}\text { Group-E } \\
(\text { mean } \pm \text { S.D) } \\
(n=30)\end{array}$ & $\begin{array}{c}\text { Group-V } \\
\text { (mean } \pm \text { S.D) } \\
(n=30)\end{array}$ & $p$-value \\
\hline Basal & $80.03 \pm 8.92$ & $82.33 \pm 5.17$ & 0.22 \\
\hline Post drug & $72.70 \pm 6.60$ & $73.03 \pm 5.73$ & 0.83 \\
\hline Intubation & $75.03 \pm 11.24$ & $78.03 \pm 5.10$ & 0.18 \\
\hline $\begin{array}{l}1 \text { minuteafter } \\
\text { intubation }\end{array}$ & $82.37 \pm 6.34$ & $83.13 \pm 10.15$ & 0.72 \\
\hline $\begin{array}{l}3 \text { minutesafter } \\
\text { intubation }\end{array}$ & $82.47 \pm 6.99$ & $84.13 \pm 7.61$ & 0.38 \\
\hline $\begin{array}{l}5 \text { minutesafter } \\
\text { intubation }\end{array}$ & $78.67 \pm 9.30$ & $82.60 \pm 9.33$ & 0.10 \\
\hline
\end{tabular}

\begin{tabular}{|c|c|c|c|}
\hline $\begin{array}{l}\text { Time Interval } \\
\text { MAP (mm Hg) }\end{array}$ & $\begin{array}{c}\text { Group-E } \\
(\text { mean } \pm S . D) \\
(n=30)\end{array}$ & $\begin{array}{c}\text { Group-V } \\
\text { (mean } \pm \text { S.D) } \\
(n=30)\end{array}$ & $p$ value \\
\hline Basal & $93.89 \pm 9.73$ & $96.57 \pm 3.87$ & 0.16 \\
\hline Post drug & $88.83 \pm 7.94$ & $90.49 \pm 5.53$ & 0.35 \\
\hline Intubation & $85.68 \pm 10.53$ & $100.94 \pm 5.50$ & $<0.001^{*}$ \\
\hline $\begin{array}{l}1 \text { minute after } \\
\text { intubation }\end{array}$ & $98.49 \pm 6.23$ & $99.70 \pm 7.08$ & 0.48 \\
\hline $\begin{array}{l}3 \text { minutes after } \\
\text { intubation }\end{array}$ & $97.06 \pm 6.97$ & $98.60 \pm 6.62$ & 0.38 \\
\hline $\begin{array}{l}5 \text { minutes after } \\
\text { intubation }\end{array}$ & $93.76 \pm 7.55$ & $97.21 \pm 7.25$ & 0.08 \\
\hline
\end{tabular}




\begin{tabular}{|c|c|c|c|c|c|}
\hline \multirow{2}{*}{$\begin{array}{l}\text { Adverse } \\
\text { Effects }\end{array}$} & \multicolumn{2}{|c|}{ Group-E $(n=30)$} & \multicolumn{2}{|c|}{ Group-V $(n=30)$} & \multirow[t]{2}{*}{$p$-value } \\
\hline & Number & $\%$ & Number & $\%$ & \\
\hline Bradycardia & 4 & 13.3 & 2 & 6.7 & 0.12 \\
\hline Hypotension & 2 & 6.7 & 2 & 6.7 & 0.99 \\
\hline Hypoxemia & 1 & 3.3 & 2 & 6.7 & 0.27 \\
\hline Shivering & 2 & 6.7 & 1 & 3.3 & 0.27 \\
\hline $\begin{array}{l}\text { Nausea \& } \\
\text { Vomiting }\end{array}$ & 2 & 6.7 & 2 & 6.7 & 0.99 \\
\hline
\end{tabular}

\section{DISCUSSION}

Laryngoscopy and endotracheal intubation are invariably associated with haemodynamic stress response with respect to cardiovascular system and these changes of stress response may be detrimental in high-risk patients especially in those with cardiovascular diseases, increased intracranial pressure and anomalies of the cerebral blood vessels. So, effective attenuation of hemodynamic response to laryngoscopy and tracheal intubation is of great importance in prevention of perioperative morbidity and mortality.

This randomized, double-blinded study was undertaken to compare the efficacy and safety of esmolol, a beta blocker and verapamil, a calcium channel blocker, in attenuation of the hemodynamic response following laryngoscopy and endotracheal intubation.

Both HR and BP are determinants of delivery and demand of oxygen. An increase in heart rate deleteriously affects both supply and demand of oxygen. BP is related to cardiac output (CO) and systemic vascular resistance (SVR). A change in either reduces the risk of arrhythmias from $13 \%$ to $4 \%$ and appears effective in reducing the risk of myocardial ischaemia.

In the present study, among the hemodynamic parameters, the baseline heart rate was similar in the two groups (esmolol and verapamil), but the heart rate findings taken after drug administration, immediately after intubation, at 1,3 and 5 minutes after intubation were found to be significantly lower in the group receiving esmolol. This is in accordance with some studies which have shown that esmolol does significantly reduce heart and attenuate the tachycardic response to laryngoscopy and intubation. ${ }^{12}$ Few studies have shown that verapamil, though reduces heart rate, very often fails to significantly attenuate the tachycardic response. ${ }^{13}$ Moreover, no study yet has directly compared the attenuating effects of esmolol with verapamil. Some studies have also shown that heart rate is the earliest and most commonly affected cardiovascular parameter during laryngoscopy and intubation ${ }^{14,15}$ which emphasizes the fact that esmolol has affected heart rate significantly in our study.
In the current study it was observed that the attenuation of systolic blood pressure was more in the group receiving esmolol, though the difference was not statistically significant in all time points except immediately after intubation ( $p$ value $<0.001)$. This could be attributed to the early effect of esmolol and verapamil on blood pressure just after intubation, the effect being more pronounced in case of esmolol in concurrence with the study of Lefrandt JD et al. ${ }^{16}$

While assessing diastolic blood pressure it was found that esmolol attenuated diastolic blood pressure more than verapamil(though not statistically significant, $\mathrm{p}>0.05$ ) similar to the studies of Rathore A et al. and Ghaus MS et al. ${ }^{17}$

While assessing the mean arterial blood pressure it was found that the attenuation of mean arterial blood pressure was more in the group receiving esmolol, though the difference was not statistically significant $(p>0.05)$ in all time points except immediately after intubation. This could be attributed to the early effect of esmolol and verapamil both on mean arterial blood pressure just after intubation (drug already given prior to that), the effect being more pronounced in case of esmolol. ${ }^{18}$

While assessing the safety issues of both the study drugs, few patients in both groups showed certain unusual electrical conduction during laryngoscopy and intubation which included mostly sinus tachycardia and ventricular premature contractions. However, none of these reached alarming levels during the study and returned to normal sinus rhythm spontaneously. It has been shown by various authors like Bedford RF et al ${ }^{19}$ and Shribman AJ et al. ${ }^{20}$ that reflex autonomic responses provoked by laryngoscopy and endotracheal intubation could cause various types of abnormal electrical conduction.

\section{Limitations of the study}

The study was conducted in a single institute on a limited number of selected patients undergone elective abdominal surgery. Also, the serum catecholamines which are the most important markers to assess the sympathoadrenal stress response to any stimulus and its level were not measured due to scarcity of the resources.

\section{CONCLUSION}

Esmololand Verapamil can effectively attenuate the hemodynamic response by limiting the extent of rises in heart rate and blood pressure. The attenuating effect has been found to be more with esmolol compared to verapamil. Both the study drugs are devoid of any serious adverse effects and thus can be safely administered during anesthesia. 


\section{REFERENCES}

1. King BD, Harris LC, Greifenstein FE, Elder JD and Dripps RD. Reflex circulatory responses to direct laryngoscopy and tracheal intubation performed during general anesthesia. Anesthesiology. 1951; 12: 556-566.

https://doi.org/10.1097/00000542-195109000-00002

2. Pernerstorfer T, Krafft P, Fitzgerald RD, Krenn CG, Chiari A, Wagner $O$, et al. Stress response to tracheal intubation: direct laryngoscopy compared with blind oral intubation. Anaesthesia. 1995; 50: 17-22.

https://doi.org/10.1111/j.1365-2044.1995.tb04506.x

3. Kats RL and Bigger JT. Cardiac arrhythmias during anaesthesia and operation. Anesthesiology. 1970; 33: 193-213.

https://doi.org/10.1097/00000542-197008000-00013

4. Tabbutt S, Nicolson SC, Adamson PC, Zhang X, Hoffman ML, Wells $\mathrm{W}$, et al. The safety, efficacy, and pharmacokinetics of esmolol for blood pressure control immediately after repair of coarctation of the aorta in infants and children: a multicenter, double blind, randomized trial. J Thorac Cardiovasc Surg. 2008; 136(2): 321-328.

https://doi.org/10.1016/j.jtcvs.2007.09.086

5. Adamson PC, Rhodes LA, Saul JP, Dick M, Epstein MR, Moate P, et al. The pharmacokinetics of esmolol in pediatric subjects with supraventricular arrhythmias. Pediatr Cardiol. 2006; 27(4): 420427.

https://doi.org/10.1007/s00246-006-1162-1

6. Garnock Jones KP. Esmolol: a review of its use in the shortterm treatment of tachyarrhythmia and the short-term control of tachycardia and hypertension. Drugs. 2012; 72(1): 109-132. https://doi.org/10.2165/11208210-000000000-00000

7. Oxorn D, Knox JW and Hill J. Bolus doses of esmolol for the prevention of perioperative hypertension and tachycardia. Can J Anaesth. 1990; 37:206-209.

https://doi.org/10.1007/BF03005471

8. Dyson A, Issac PA, Pennant JH, Giesecke AH and Lipton JM. Esmolol attenuates cardiovascular responses to intubation. Anesth Analg.1990; 71:675-680.

https://doi.org/10.1213/00000539-199012000-00017

9. Miller DR, Martineau RJ, Wynands JE and Hill J. Bolus administration of esmolol for controlling the haemodynamic response to tracheal intubation. The Canadian multicentre trial. Can J Anesth. 1991; 38:849-858.

https://doi.org/10.1007/BF03036959

10. Yaku H, Mikawa K, Maekawa $\mathrm{N}$ and Obara H. Effect of verapamil on the cardiovascular responses to tracheal intubation. $\mathrm{Br} \mathrm{J}$ Anaesth. 1992; 68:85-89. https://doi.org/10.1093/bja/68.1.85

11. Singh $H$, Vichitvejpaisal $P$, Gaines $G Y$ and White PF. Comparative effect of lidocaine,esmolol and nitroglycerine in modifying the haemodynamic response to laryngoscopy and intubation. $\mathrm{J}$ Clin Anaesth. 1995; 7: 528. https://doi.org/10.1016/0952-8180(94)00013-T

12. Sharma S, Mitra S, Grover VK and Kalra R. Esmolol blunts the hemodynamic responses to tracheal intubation in treated hypertensive patients. Can J Anaesth. 1996; 43:778-782. https://doi.org/10.1007/BF03013028

13. Kindler $\mathrm{CH}$, Schumacher PG, Schneider $\mathrm{MC}$ and Urwyler $\mathrm{A}$. Effects of intravenous lidocaine and / or esmolol on haemodynamic responses to laryngoscopy and intubation: a double blind controlled clinical trial. J Clin Anaesth. 1996; 8(6):491-496. https://doi.org/10.1016/0952-8180(96)00109-2

14. Mikawa K, Nishina K, Maekawa $\mathrm{N}$ and Obara H. Attenuation of cardiovascular responses to tracheal extubation: Verapamil versus Diltiazem. Anesth Analg. 1996; 82: 1205-1210. https://doi.org/10.1213/00000539-199606000-00018

15. Mikawa K, Nishina K, Maekawa N and Obara H. Comparison of nicardipine, diltiazem and verapamil for controlling the cardiovascular responses to tracheal intubation. $\mathrm{Br} \mathrm{J}$ Anaesth. 1996; 76: 221-226.

https://doi.org/10.1093/bja/76.2.221

16. Lefrandt JD, Heitman J, Sevre K, Castellano M, Hausberg M, Fallon $\mathrm{M}$, et al. Contrasting effects of verapamil and amlodipine on cardiovascular stress responses in hypertension. $\mathrm{Br} \mathrm{J}$ Clin Pharmacol. 2001; 52: 687-692. https://doi.org/10.1046/j.0306-5251.2001.01507.x

17. Rathore A, Gupta HK, Tanwar GL and Rehman H. Attenuation of the pressure response to laryngoscopy and endotracheal intubation with different doses of esmolol. Indian J Anesth. 2002; 46(6):449-452.

18. Ghaus MS, Singh V, Kumar A, Wahal R, Bhatia VK and Agaewal J. A study of cardiovascular response during laryngoscopy and intubation and their attenuation by ultrashort-acting alpha-blocker Esmolol. Indian J Anaesth. 2002; 46: 104-106.

19. Kumar S, Mishra MN, Mishra LN and Bhatia S. Comparative study of the efficacy of iv esmolol, ditiazem and magnesium sulphate in attenuating haemodynamic response to laryngoscopy and tracheal intubation. Indian J Anaesth. 2003; 47: 41-44.

20. Bakiye U, Ogurlu M and Gezer E. Effects of esmolol, lidocaine and fentanyl on hemodynamic responses to endotracheal intubation: A comparative study. Clinical Drug Investigation. 2007; 27:269-277.

https://doi.org/10.2165/00044011-200727040-00006

\footnotetext{
Author's Contribution:

NC, SR-Concept, design of study and literature search, experimental studies; DS, SR- Data acquisition, data analysis, statistical analysis; AB, DB-Manuscript preparation; AA- Manuscript editing and manuscript review.

Work Attributed to:

K.P.C Medical College and Hospital, Kolkata.

Orcid ID:

Dr. Arunava Biswas - (i) https://orcid.org/0000-0002-9676-3410

Source of Funding: None, Conflict of Interest: None
} 